\title{
Can pre-race aspirin prevent sudden cardiac death during marathons?
}

\author{
Arthur J Siegel, ${ }^{1,2}$ Timothy D Noakes $^{3}$
}

As if reprising the index case of Pheidippides in $490 \mathrm{BC}$, the sudden cardiac death of a 32-year-old modern-day warrior at mile 20 in the 2016 London marathon mandates an expedited search to prevent such tragic events based on novel insights

\footnotetext{
${ }^{1}$ McLean Hospital, Belmont, Massachusetts, USA

${ }^{2}$ Harvard Medical School, Boston, Massachusetts, USA

${ }^{3}$ Department of Human Biology, University of Cape

Town, Cape Town, South Africa
}

Correspondence to Dr. Arthur J Siegel, McLean Hospital, 115 Mill Street, Belmont, MA 02478, USA; asiegel@partners.org into the underlying cause (figure 1). ${ }^{12}$ Although the cardiac findings in this case have not been released, an acute coronary event is most likely as the most common cause of sudden cardiac death in men over the age of 30 years including among experienced runners in that event. ${ }^{3-5}$

While the overall incidence of sudden cardiac death during marathons is low, cardiac arrests occur in roughly 1 in 50000 finishers. $^{6}$ Based on 59 cases with a mean age of 42 years in a 10 -year prospective registry of American road races since 2000 , male sex and the marathon were the only significant risk factors for cardiac arrest. ${ }^{7}$ Atherosclerotic heart disease was the predominant underlying cause in same-aged runners in a concurrent Parisian registry. ${ }^{8}$ Marathon running thereby illustrates the triggering of acute myocardial infarction by strenuous exercise in middle-aged males with underlying non-obstructive coronary atherosclerosis. ${ }^{9}$

\section{RATIONALE FOR TARGETED PREVENTION}

Supported by a $44 \%$ reduction in first acute myocardial infarctions in healthy middleaged men in the Physicians Health Study, a randomised controlled primary prevention trial, ${ }^{10}$ the International Marathon Medical Directors Association (IMMDA) has recommended prerace aspirin for males over the age of 40 years with approval by 

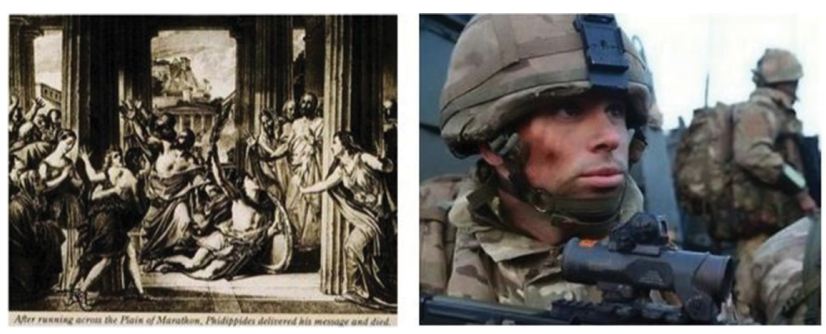

Figure 1 Modern and ancient warriors.

their physicians after considering risks such as gastrointestinal bleeding or allergy. ${ }^{11}$ This strategy is concordant with clinical guidelines endorsing aspirin for primary prevention in persons at high cardiovascular risk, which includes middle-aged males at increased short-term risk for acute myocardial ischaemia. ${ }^{12} 13$

IMMDA's advisory is analogous to that proposed for firefighters, who are at increased risk for sudden cardiac death during emergency duties in part related to procoagulant effects as shown in athletes after strenuous physical exercise. ${ }^{14-16}$ Attenuation of training-induced prothrombotic effects by aspirin in firefighters would apply as well to runners based on atherothrombosis as the shared pathogenic paradigm. ${ }^{17} \mathrm{In}$ contrast to continuous prophylaxis to cover unpredictable risk in firefighters, prerace use may suffice for marathoners who are at otherwise low cardiovascular risk as assessed by 10 -year Framingham measures.

Assessment of coronary artery calcification, which independently predicts incident coronary heart disease and death in males aged 32 to 46 years, ${ }^{18}$ may be useful for stratifying the utility of aspirin for marathoners with such evidence for atherosclerosis. ${ }^{19}$ This strategy may be especially relevant for habitual marathoners whose paradoxically

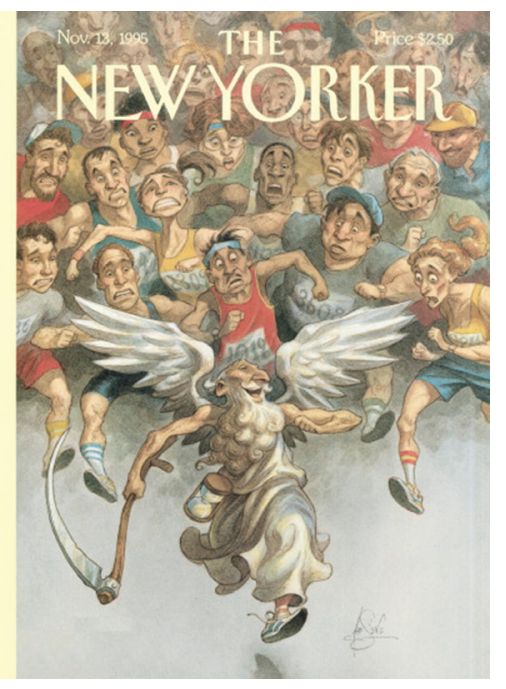

Figure 2 Father Time running a marathon, by Peter de Seve, the New Yorker, 13 November 1995. higher scores correlate inversely with eventfree survival. ${ }^{20}$ This finding indicates short-term risk for acute cardiac events associated with atherosclerotic plaque burden, confounding the benefit of enhanced longevity with this lifestyle. ${ }^{21-23}$

\section{The case for using prerace aspirin in middle-aged males}

Given 285040 US male marathoners over the age of 40 in $2015,{ }^{24}$ IMMDA's advisory warrants expedited attention given a greater than twofold increase in race-related cardiac arrests since 2005. ${ }^{7}$ We therefore encourage medical directors to follow Rio de Janeiro's lead by informing entrants of IMMDA's advisory, hoping to avert cardiac arrests as occurred at their last two races (personal communication, Paulo Alfono Loriega de Menezes, MD, medical director, Rio de Janeiro marathon).

Prerace aspirin provides runners pre-emptively with the only pharmacological agent with a class $1 \mathrm{~A}$ recommendation for pre-hospital administration in the event of an acute coronary syndrome. Such usage may reduce the increasing frequency of emergent post-race percutaneous coronary angioplasties and bypass surgery, as occurred after the most recent Boston and Chicago marathons. ${ }^{2526}$ 'Just because the cardiac risk is low, doesn't mean it can't be lower', argues Amby Burfoot, Runners World's editor-at-large and former Boston marathon champion. ${ }^{27}$

IMMDA's advisory enables middle-aged males to make more informed decisions regarding the cardiovascular benefits of marathon training and pre-race aspirin use for risk reduction during races (figure 2). ${ }^{28}$ The lifetime benefit of reducing risk for sudden cardiac death through marathon training can be accomplished with attenuation of its transient risk during races (box 1). ${ }^{9}{ }^{29}$ In lieu of a randomised controlled primary prevention trial in marathoners, which lacks feasibility due to the low frequency of index events, prospective registries can be used to assess aspirin's efficacy once usage gains acceptance among runners contingent on wider support by the marathon medical community.

The goal of reducing sudden cardiac death in middle-aged males during marathons
Box 1 Rationale for using prerace aspirin to prevent sudden cardiac death during marathons

- Aspirin reduces first acute myocardial infarctions in healthy males by $44 \%$.

- Acute myocardial infarction is the most common cause of sudden cardiac death in males over the age of 30 including during marathons.

- Use of prerace low-dose aspirin is prudent to prevent race-related sudden cardiac death.

is realistic in our view, having successfully curtailed race-related fatalities due to water intoxication in young females through a robust consensus process. ${ }^{3031}$ As it is safe, inexpensive and readily available worldwide, aspirin is ready for prime time in middle-aged males as a high-risk subgroup. Based on a predominance of current clinical evidence, this remedy, known to Hippocrates in the time of Pheidippides, may enhance the heroic dimensions of a sport celebrating his legacy by reducing re-enactments of his tragic demise.

\section{Rationale}

If aspirin conclusively prevents first myocardial infarctions in healthy middle-aged males, prerace aspirin may reduce such events during marathons.

\section{MMDA recommendation}

Long-distance runners, especially men over the age of 40, are advised in the absence of specific contraindications to take prerace aspirin if approved by their personal physician after discussion of its risks and benefits.

Contributors Both authors contributed equally to the viewpoints in this editorial.

\section{Competing interests None declared.}

Provenance and peer review Not commissioned; externally peer reviewed.

\section{(1) OPEN ACCESS}

Open Access This is an Open Access article distributed in accordance with the Creative Commons Attribution Non Commercial (CC BY-NC 4.0) license, which permits others to distribute, remix, adapt, build upon this work non-commercially, and license their derivative works on different terms, provided the original work is properly cited and the use is non-commercial. See: http:// creativecommons. org/licenses/by-nc/4.0/

(C) Article author(s) (or their employer(s) unless otherwise stated in the text of the article) 2017. All rights reserved. No commercial use is permitted unless otherwise expressly granted.

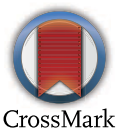


To cite Siegel AJ, Noakes TD. Br I Sports Med 2017;51:1579-1581.

Received 29 August 2016

Revised 8 May 2017

Accepted 16 May 2017

Published Online First 19 July 2017

Br J Sports Med 2017;51:1579-1581.

doi:10.1136/bjsports-2016-096917

\section{REFERENCES}

1 Siegel AJ. Pheidippides redux: reducing risk for acute cardiac events during marathon running. Am J Med 2012;125:630-5.

2 London marathon runner David Seath dies three miles from finish line after cardiac arrest. Independent. Monday 25 April 2016. http://www.independent.co. uk/news/uk/home-news/london-mararthon-deathdavid-seath-soldier-dies-three-miles-from-finidh-lineafter-suffering-cardiac-a6999411.htmlgallery.

3 Bagnall RD, Weintraub RG, Ingles J, et al. A prospective study of sudden cardiac death among children and young adults. N Engl J Med 2016;374:2441-52.

4 Tunstall Pedoe DS. Marathon cardiac deaths: the London experience. Sports Med 2007:37:448-50.

5 James J, Merghani A, Sharma S. Sudden death in marathon runners. Card Electrophysiol Clin 2013;5:43-51.

6 Hart L, Marathon-related cardiac arrest Clin J Sport Med 2013;23:409-10.

$7 \mathrm{Kim} \mathrm{JH}$, Malhotra R, Chiampas G, et al. For the RACER Study Group. cardiac arrest during long-distance running races. N Engl J Med 2012;366:130-40.

8 Gerardin B, Collet JP, Mustafic H, et al. Registry on acute cardiovascular events during endurance running races: the prospective RACE Paris registry. Eur Heart $J$ 2016:37:2531-41.

9 Smyth A, O'Donnell M, Lamelas P, et al. Physical activity and anger or emotional upset as triggers of acute myocardial infarction: the INTERHEART Study. Circulation 2016;1345:1059-67.

10 Steering Committee of the Physicians' Health Study Research Group. Final report on the aspirin component of the Ongoing Physicians' Health Study. N Engl J Med 1989:321:129-35.

11 Siegel AJ. IMMDA Advisory, 2015: pre-race aspirin to prevent heart attack and/or cardiac arrest during long distance running. Available at: http://immda.org/wpcontent/uploads/2015/08/Spring-2015-Pre-raceASA. pdf (accessed 14 Jul 2016)

12 Siegel AJ. Pre-race aspirin usage to prevent cardiac arrest in susceptible runners during marathons: is opportunity knocking? Open Heart 2015;2:e000102.

13 Siegel AJ, Bhatti NA, Wasfy JH. Reprising ramadanrelated angina pectoris: a potential strategy for risk reduction. Am J Case Rep 2016;17:841-4.

14 Kales SN, Smith DL. Firefighting and the heart: implications for prevention. Circulation 2017;135:1296-9.

15 Siegel AJ, Stec JJ, Lipinska I, et al. Effect of marathon running on inflammatory and hemostatic markers. Am J Cardiol 2001;88:918-20.

16 Huskens D, Roest M, Remijn JA, et al. Strenuous exercise induces a hyperreactive rebalanced haemostatic state that is more pronounced in men. Thromb Haemost 2016:115:1109-19.

17 Smith DL, Horn GP, Woods J, et al. Effect of aspirin supplementation on hemostatic responses in firefighters aged 40 to 60 years. Am J Cardiol 2016;118:275-80.

18 Carr JJ, Jacobs DR, Terry JG, et al. Association of coronary artery calcium in adults aged 32 to 46 years with incident coronary heart disease and death. JAMA Cardiol 2017; 2:391

19 Möhlenkamp S, Leineweber K, Lehmann $N$, et al. Coronary atherosclerosis burden, but not transient troponin elevation, predicts long-term outcome in recreational marathon runners. Basic Res Cardiol 2014;109:391-5.

20 Tsiflikas I, Thomas C, Fallmann C, et al. Prevalence of subclinical coronary artery disease in middle-aged, male marathon runners detected by cardiac CT. Rofo 2015:187:561-8.

21 Merghani A, Maestrini V, Rosmini S, et al. Prevalence of subclinical coronary artery disease in masters endurance athletes with a low atherosclerotic risk profile. Circulation 2017: CIRCULATIONAHA.116.026964.

22 Aengevaeren VL, Mosterd A, Braber TL, et al. The relationship between lifelong exercise volume and coronary atherosclerosis in athletes. Circulation 2017:CIRCULATIONAHA.117.027834 (Originally published 27 Apr 2017).

23 Lee DC, Brellenthin AG, Thompson PD, et al. Running as a key lifestyle medicine for longevity. Prog Cardiovasc Dis 2017.

24 Running USA: 2016 state of the sport: U.S. road race trends. http://www.runningusa.org/state-of-sport-ustrends-2015 (accessed 12 Apr 2016)

25 Boston Marathon after suffering heart attack. 84-yearold man completes Boston Marathon after suffering heart attack. April 21, 2017. 11:37 PM. http://Boston. cbslocal.com/2017/04/21/84-year-old.jimmie.green. completes.

26 Kuzma C. Nurse who helped save marathoner: "Last time I saw him he was dead". (/person/cindy-kuzma). 2016. Friday, October 7 http://www.runnersworld. com/Chicago-marathon-nurse-who-helped-savemarathoner-last-time-i-saw-him-he-was-dead.

27 Burfoot A. New advice on common drugs and heart health for runners. 2015. Runners World online, July 16 http: //www.runnersworld.com/tag/heart.

28 Noakes T. Time to quit that marathon running? Not quite yet! Basic Res Cardiol 2014:109:395-6.

29 Mittleman MA, Maclure M, Tofler GH, et al. Triggering of acute myocardial infarction by heavy physical exertionprotection against triggering by regular exertion. $N$ Eng/ I Med Overseas Ed 1993:329:1677-83.

30 Siegel AJ. Fatal water intoxication and cardiac arrest in runners during marathons: prevention and treatment based on validated clinical paradigms. Am J Med 2015;128:1070-5.

31 Hew-Butler T, Rosner MH, Fowkes-Godek S, et al. Statement of the 3rd International Exercise Associated Hyponatremia Consensus Development Conference, Carlsbad, California, 2015. Br J Sports Med 2015;49:1432-46

32 Hunter AL, Shah AS, Langrish JP, et al. Fire simulation and Cardiovascular Health in Firefighters. Circulation 2017;135:1284-95. 